Natural Hazards and Earth System Sciences (2004) 4: 469-474

SRef-ID: 1684-9981/nhess/2004-4-469

(C) European Geosciences Union 2004

\title{
Critical conditions of bed sediment entrainment due to debris flow
}

\author{
M. Papa ${ }^{1}$, S. Egashira ${ }^{2}$, and T. Itoh ${ }^{2}$ \\ ${ }^{1}$ Department of Civil Engineering, Salerno University, Italy \\ ${ }^{2}$ Department of Civil and Environmental Systems Engineering, College of Science and Engineering, Ritsumeikan Univ., Japan
}

Received: 7 April 2004 - Revised: 30 June 2004 - Accepted: 19 July 2004 - Published: 2 August 2004

Part of Special Issue "Monitoring and modeling of landslides and debris flows"

\begin{abstract}
The present study describes entrainment characteristics of bed material into debris flow, based on flume tests, numerical and dimensional analyses. Flume tests are conducted to investigate influences of bed sediment size on erosion rate by supplying debris flows having unsaturated sediment concentration over erodible beds. Experimental results show that the erosion rate decreases monotonically with increase of sediment size, although erosion rate changes with sediment concentration of debris flow body.

In order to evaluate critical condition of bed sediment entrainment, a length scale which measures an effective bed shear stress is introduced. The effective bed shear stress is defined as total shear stress minus yield stress on the bed surface. The results show that critical entrainment conditions can be evaluated well in terms of Shields curve using the effective bed shear stress instead of a usual bed shear stress.
\end{abstract}

\section{Introduction}

Debris flow size will increase when entrainment of bed sediment takes place, and otherwise will decrease. Such change of debris flow characteristics can be predicted numerically by using governing equations, a flow resistance equation and an erosion rate formula. Such studies have been conducted by several researchers (e.g. Egashira, 1993a, b; Takahashi et al., 1986, 1988, 1991; Nakagawa et al., 1996). They obtained interesting debris flow characteristics such as flow velocity, flow depth and sediment concentration from the inception to the stop along the reach. However, there are notable differences between erosion rate formulas developed by each researcher.

Egashira (1993a) proposed an erosion rate formula supposing that bed slope is always adjusted to its equilibrium value in case of debris flows over erodible bed. A debris

Correspondence to: T. Itoh

(itoht@se.ritsumei.ac.jp) flow either erodes bed material or leaves sediment on the bed from the body so as to form equilibrium bed slope.

$$
\frac{E}{\bar{u}}=c_{*} \tan \left(\theta-\theta_{e}\right)
$$

in which $E$ is the erosion rate, $\bar{u}$ is the depth averaged velocity of debris flow body, $c_{*}$ is the sediment concentration in the non-flowing layer by volume, $\theta$ is the bed slope, $\theta_{e}$ is the equilibrium bed slope corresponding to sediment concentration of the debris flow body as follows.

$\tan \theta_{e}=\frac{(\sigma / \rho-1) \bar{c} \tan \phi_{s}}{(\sigma / \rho-1) \bar{c}+1}$

in which $\sigma$ is the mass density of sediment particles, $\rho$ is the mass density of water, $\bar{c}$ is the depth averaged sediment concentration of debris flow by volume and $\phi_{S}$ is the interparticle friction angle of sediment particles. Sediment deposition takes place when the bed slope is milder than the equilibrium bed slope resulting in the negative value of erosion rate. Takahashi et al. (1986) also proposed a formula for erosion rate and another for deposition rate, separately.

In the previous author's study, Egashira et al. (2001) pointed out that the bed entrainment is affected by grain size of bed sediment. Actually, it is often observed that large stones cannot be removed even in a reach where erodible regime of debris flow dominates. Therefore, we need a formula for erosion rate to evaluate such a phenomena. In order to develop an erosion rate formula of debris flow, the present study describes the entrainment characteristics in case that bed sediment is different from the solid material in debris flows.

\section{Experimental facility and procedures}

Figure 1 shows the experimental flume, which is $10.0 \mathrm{~cm}$ wide, $20.0 \mathrm{~cm}$ high and $12.0 \mathrm{~m}$ long. The flume is divided into two parts by a $10.0 \mathrm{~cm}$ high sand stopper. In the upstream reach, a debris flow with characteristics as required 


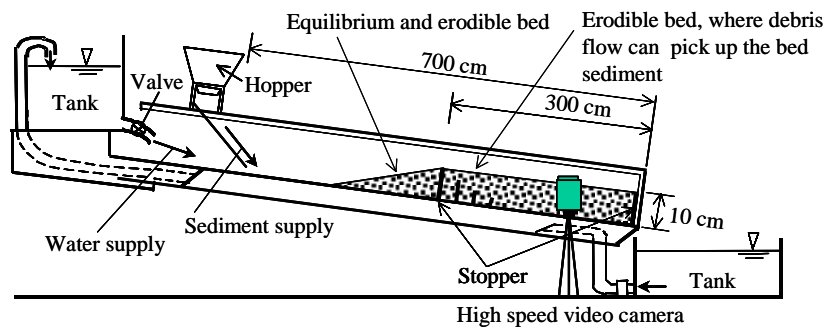

Fig. 1. Schematics of experimental flume.

for tests can be produced by water and sediment supply. Sediment bed is set up smoothly by using the same material of the supplied debris flow body, and the surface slope is adjusted to the equilibrium slope corresponding to the sediment concentration of supplied debris flow in order to maintain a steady saturated flow. In the downstream reach, a $10.0 \mathrm{~cm}$ high sand stopper is set at the lower end and an erodible bed, $10.0 \mathrm{~cm}$ thick, is made of sediment with a uniform grain size. The bed surface of this part is always kept the same as slope of channel at the beginning of tests. The debris flow produced in the upstream side has a saturated nature and an equilibrium bed slope. However, it can erode bed sediment in the downstream reach because bed slope is steeper than equilibrium slope. The step and pool type's works are set near upstream area in the downstream reach, in which bed sediment are eroded, in order to avoid the bed fluctuation due to debris flow erosion.

Experimental conditions are shown in Table 1. A uniform grain size, $d_{0}$, of $0.218 \mathrm{~cm}$ is used to form the debris flow in all cases. Inflow sediment and water mixture discharge rate, $q_{m}$, is set a constant value at the upper boundary where dry sands are mixed with supply water to produce a required debris flow. Flux sediment concentration, $c_{f}$, of supplied debris flow is about $0.05,0.10$ and 0.15 by volume in some cases, respectively. Herein, flux sediment concentration, $c_{f}$, is defined as $c_{f}=q_{s} / q_{m}$, in which, $q_{s}$ is the sediment discharge rate. Four kinds of uniform sediment, which are $0.218 \mathrm{~cm}$, $0.438 \mathrm{~cm}, 0.8 \mathrm{~cm}, 1.1 \mathrm{~cm}$ in diameter, are used for erodible bed, respectively. The mean value of the internal friction angle of sediment particles of $d_{0}=0.218 \mathrm{~cm}$ is $38.7^{\circ}$. The solid material in the erodible bed reach of the flume is always saturated by water.

Several runs are performed in the same experimental condition in order to obtain reliable data. In all cases, sediment and water mixture discharge at the lower end of the flume, erosion depth of bed sediment, and flow depth and bed elevation at a fixed point on the erodible bed reach are measured. In case of $d=d_{0}$, sediment discharge and discharge of sediment and water mixture are measured at interval of two seconds by using buckets. In addition, the flux sediment concentration is calculated at the downstream end for each grain size by separating eroded material from that of supplied debris flow. The erosion depth of bed sediment is measured by using point gauges immediately after stopping the debris flow supply. Temporal changes for $h$ and $z_{b}$ and ver-

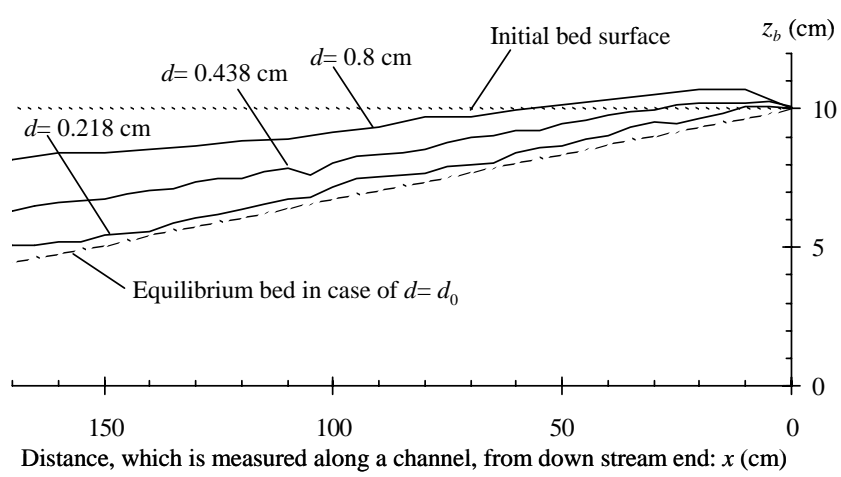

Fig. 2. Longitudinal bed profile obtained by flume test.

tical velocity distribution, $u(z)$ in the equilibrium stage, are measured at a fixed point $60.0 \mathrm{~cm}$ upstream from the lower end of the flume by pursuing the flow with high speed video camera and analyzing the images. Herein, an equilibrium stage means that no bed erosion takes place in downstream reach. Therefore, in each experiment, sediment is continuously supplied until an entrainment of bed sediment does not take place.

\section{Results and discussions}

Figure 2 shows the experimental results on the longitudinal profiles of bed surface in equilibrium condition in case that flux sediment concentration of supplied debris flow is about 0.10 and that sediment size of erodible bed is $d=0.218 \mathrm{~cm}$, $0.438 \mathrm{~cm}$ and $0.8 \mathrm{~cm}$, respectively. In the figure, the prediction of bed profile in the equilibrium flow condition is shown, because equilibrium bed slope in the steady flow condition is uniquely determined by sediment concentration in case that the movements of sediment particles are laminar and that bed sediment size is same as sediment size of debris flow body (Egashira et al., 1997a, b). Moreover, those longitudinal bed profiles are measured immediately after sediment and water from upstream end is stopped and flow condition seems to reach equilibrium stages. It is remarkable that the bed erosion is affected by the bed sediment size and that bed degradation is smaller when the bed sediment size is coarser.

Figure 3 shows velocity distributions in an equilibrium stage in case of $d=0.218 \mathrm{~cm}, 0.438 \mathrm{~cm}$ and $0.8 \mathrm{~cm}$, respectively. If the sediment size of debris flow body is same as bed sediment size, the velocity profile is the same shape as in case of the flow over an erodible, equilibrium bed. When the bed sediment size increases, the velocity distribution becomes similar to a velocity profile in flow over the rigid bed. Those mean that, in every equilibrium stage, shear stress due to shear rate should be zero on the bed surface in case of $d=d_{0}$, and whereas be non-zero in case of $d>d_{0}$. 
Table 1. Experimental conditions.

\begin{tabular}{cccccc}
\hline Run & $\begin{array}{c}\text { Bed material } \\
\text { size, } d(\mathrm{~cm})\end{array}$ & $\begin{array}{c}\text { Channel } \\
\text { slope }\left(^{\circ}\right)\end{array}$ & $\begin{array}{c}\text { Bed slope } \\
\text { in down stream } \\
\text { reach } \theta\left(^{\circ}\right)\end{array}$ & $\begin{array}{c}\text { Supply condition } \\
\text { from upstream } \\
\text { of channel }\end{array}$ \\
\hline 030 & 0.438 & 10 & 8.53 & 0.0893 & 98.4 \\
031 & 0.438 & 12 & 10.2 & 0.140 & 96.3 \\
032 & 0.438 & 12 & 10.2 & 0.155 & 98.0 \\
133 & 0.218 & 10 & 8.53 & 0.101 & 97.8 \\
034 & 0.218 & 10 & 8.21 & 0.0953 & 99.2 \\
035 & 0.8 & 10 & 8.99 & 0.104 & 99.2 \\
036 & 0.8 & 10 & 8.68 & 0.156 & 101 \\
137 & 0.438 & 7.7 & 5.60 & 0.0476 & 100 \\
038 & 0.8 & 7.7 & 5.88 & 0.0472 & 99.5 \\
039 & 0.8 & 8.3 & 5.84 & 0.0288 & 46.3 \\
040 & 0.8 & 13.6 & 11.7 & 0.151 & 48.1 \\
\hline
\end{tabular}
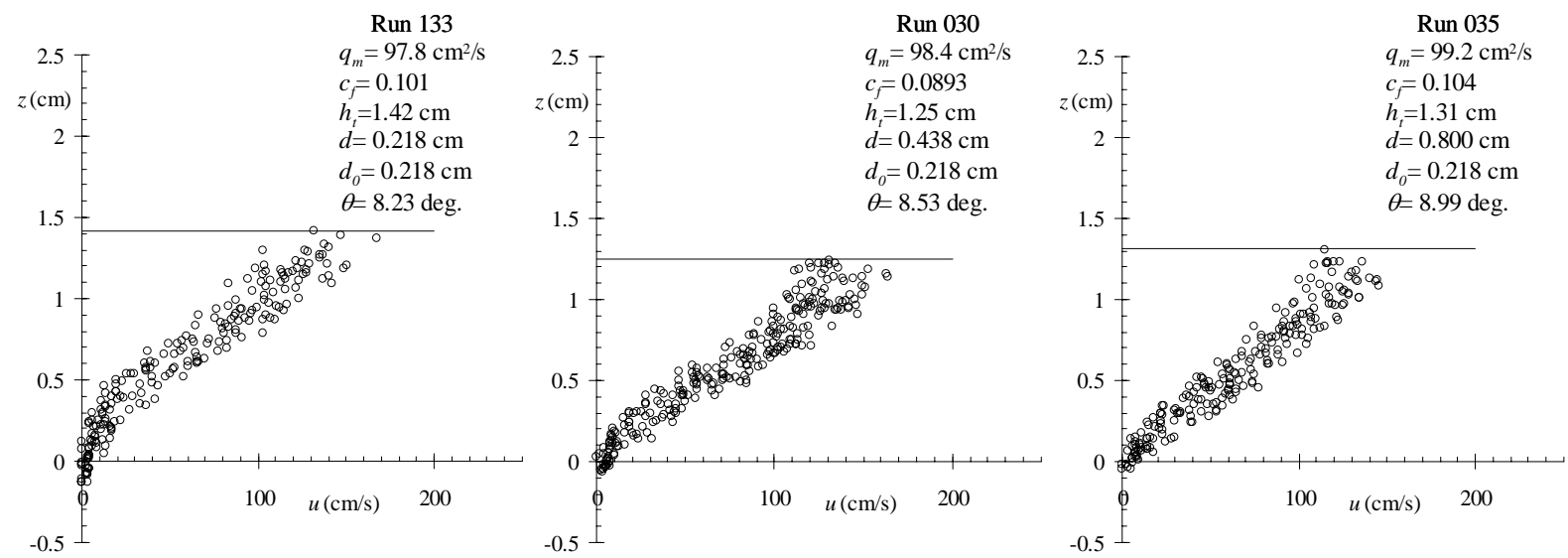

Fig. 3. Velocity distributions in equilibrium stages in case that flux sediment concentration, $c_{f}$, is about 0.10 .

\section{Critical condition of bed material}

\subsection{Flow model}

A steady, longitudinally uniform, uni-directional flow of a sediment-water mixture is illustrated in Fig. 4. The momentum conservation equations for such a simple flow reduce to;

$\tau(z)=\int_{z}^{h} \rho_{m} g \sin \theta d z$

$p(z)=\int_{z}^{h} \rho_{m} g \cos \theta d z$

in which $h_{t}$ is the flow depth, $g$ is the acceleration due to gravity, $z$ is the bed-normal coordinate, $\theta$ is the inclination from horizontal, $\tau$ is the shear stress in planes parallel to the bed, $p$ is the isotropic component of stress, i.e. "pressure", $\rho_{m}$ is the mass density of the sediment mixture; $\rho_{m}=(\sigma-\rho) c+\rho$, in which $\sigma$ is the mass density of sediment particles, $\rho$ is the mass density of water and $c$ is the sediment concentration by volume.
Egashira et al. (1989, 1997a, b) suggest that energy dissipation in debris flows is mainly dominated by static interparticle contacts, inelastic particle collisions and turbulence of interstitial water, which leads to

$\tau=\tau_{y}+\tau_{d}+\tau_{f}$

$p=p_{s}+p_{d}+p_{w}$

in which $\tau_{y}$ is the yield stress, $\tau_{d}$ is the shear stress due to inelastic particle-particle collisions, $\tau_{f}$ is the shear stress supported by interstitial water, $p_{s}$ is the pressure of static interparticle contacts, $p_{d}$ is the dynamic pressure due to inelastic particle collisions, $p_{w}$ is the isotropic pressure of water. If the turbulent suspension of particles is negligibly small, and thus the particle motion is laminar, the pore water pressure, $p_{w}$, satisfies

$p_{w}(z)=\rho g(h-z) \cos \theta$ 


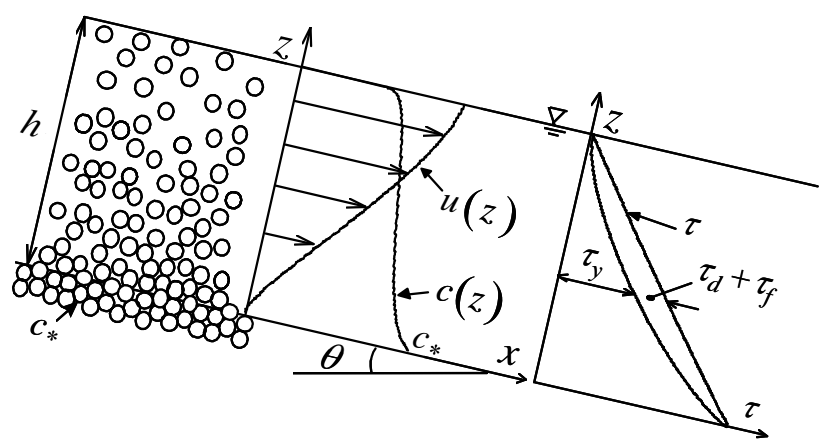

Fig. 4. Schematic of steady and longitudinally uniform debris flow over erodible bed.

Moreover, they applied Miyamoto's study (1985) on inelastic particle collisions, and presented constitutive equations as follows (Egashira et al., 1997a, b; Itoh et al., 1999).

$\tau_{y}=p_{s} \tan \phi_{s}$

$\tau_{d}=k_{d}\left(1-e^{2}\right) \sigma d^{2} c^{1 / 3}|\partial u / \partial z|(\partial u / \partial z)$

$\tau_{f}=\rho v_{f}(\partial u / \partial z)+\rho k_{f} d^{2}(1-c)^{5 / 3} c^{-2 / 3}|\partial u / \partial z|(\partial u / \partial z)$

$p_{d}=k_{d} \sigma e^{2} d^{2} c^{1 / 3}(\partial u / \partial z)^{2}$

$p_{s} /\left(p_{s}+p_{d}\right)=\left(c / c_{*}\right)^{1 / 5}$

in which $\phi_{s}$ is the interparticle friction angle, $e$ is the restitution coefficient of particle to particle, $d$ is the sediment particle size, $u$ is the local velocity in the flow direction, $c_{*}$ is the sediment concentration by volume in non-flowing layer and $k_{d}$ and $k_{f}$ are empirical constants $\left(k_{d}=0.0828, k_{f}=0.16\right)$.

\subsection{Definition of critical bed shear stress for bed erosion}

Figure 5 shows schematics of flow velocity and shear stress distribution for an unsaturated debris flow running down over an erodible bed. In Fig. 5a, $d$ is coarser than $d_{0}$, of debris flow body, and in Fig. 5b, $d$ is the same as the sediment size, $d_{0}$, and $\tau$ is the total shear stress or the stress component of body force in the flow direction, $\tau_{y}$ is the yield stress caused by particle contacts, and $\delta$ is the critical depth from bed surface to the level where $\tau$ is equal to $\tau_{y}$. According to constitutive relations developed by Egashira et al. (1997 a, b), a shear flow which is shown in Fig. 5 takes place in accordance with $\tau-\tau_{y}$.

Bed erosion due to unsaturated debris flow is explained using Fig. 5 as follows. If bed sediment size, $d$, is much greater than $\delta$, no erosion takes place. In contrast, bed sediment are eroded in case that bed sediment size, $d$, is smaller than $\delta$.

Let us discuss critical condition for sediment movement in the critical depth, $\delta$, as shown in Fig. 5a. Effective shear stress on the bed should be $\tau_{b}-\tau_{y b}$; that is responsible for
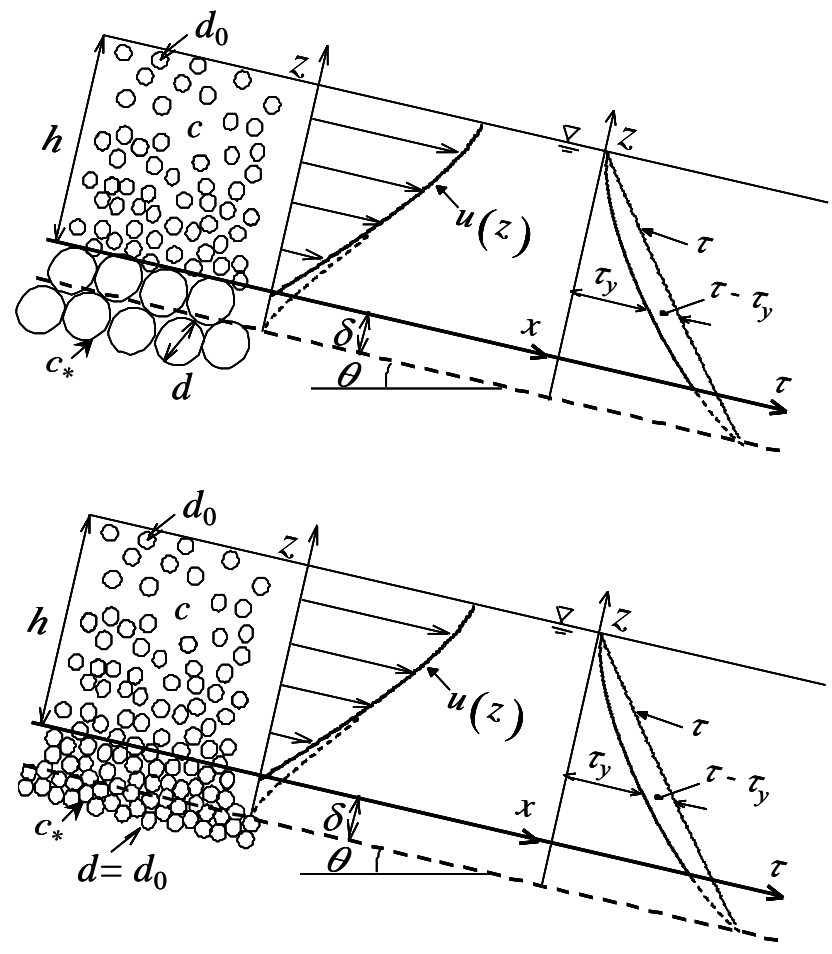

Fig. 5. Schematic of debris flow over a bed of uniform grain size, $d$. (a) $d$ is coarser than $d_{0}$. (b) $d$ is as same as the sediment size, $d_{0}$, of debris flow body.

shear rate. Therefore, it is expected that $\tau_{b}-\tau_{y b}$ is dimensionally expressed as follows.

$\tau_{b}-\tau_{y b}=k(\sigma-\rho) g \delta$

in which $k$ is the coefficient with unit order, $\tau_{y b}$ is the yield stress on the bed surface, $z=0$.

Substituting Eqs. (3), (8) and (12) into Eq. (13) yields the following equation using the size of bed sediment particles, $d$.

$\frac{\tau_{b}-\tau_{y b}}{(\sigma-\rho) g d}=(G-Y) \tau_{*}=k \frac{\delta}{d}$

$\tau_{*}=\frac{u_{\tau}^{2}}{(\sigma / \rho-1) g d}, \quad u_{\tau}=\sqrt{g h \sin \theta}$,

$G=(\sigma / \rho-1) \bar{c}+1$,

$Y=\left(\bar{c} / c_{*}\right)^{1 / 5}(\sigma / \rho-1) \bar{c} \frac{\tan \phi_{s}}{\tan \theta}$

in which $\bar{c}$ is depth-averaged sediment concentration.

In a clear water flow on the sediment bed, the yield stress on the bed, $\tau_{y b}$, is equal to zero. Taking into account critical condition of bed sediment entrainment, the flow condition such as no erosion of bed sediment corresponds to critical condition of sediment movement of bed sediment particles. It is expected that Eq. (14) is rewritten in case of clear water flow, $\bar{c}=0$, as follows.

$\left.\frac{\tau_{b}}{(\sigma-\rho) g d}\right|_{c}=\tau_{* c}=\left.k \frac{\delta}{d}\right|_{c}$ 


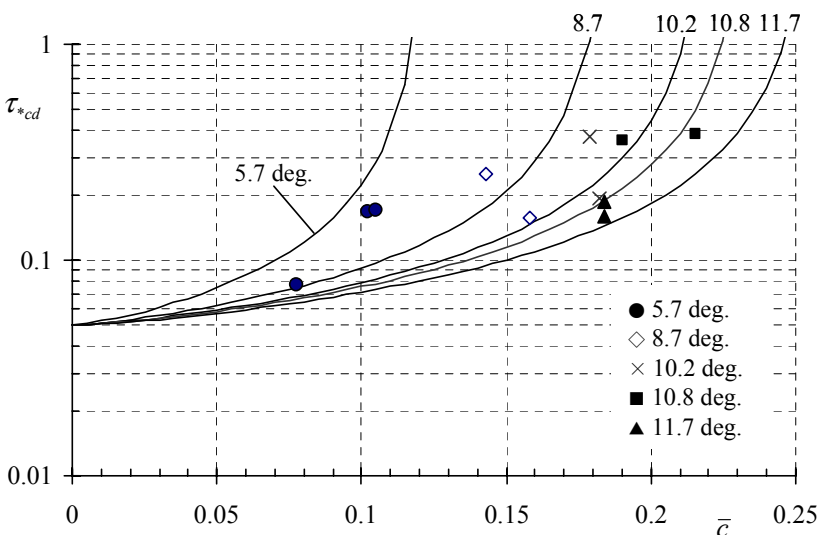

Fig. 6. Relationship between depth-averaged sediment concentration and non-dimensional effective bed shear stress.

The under-suffix "c" means "critical condition" of bed sediment movement. The parameter, $\tau_{* c}$, is Shields parameter for sediment movement.

Herein, in the critical condition of bed sediment erosion, Eq. (14) is deduced as follows.

$$
\left.\frac{\tau_{b}-\tau_{y b}}{(\sigma-\rho) g d}\right|_{c}=\left.(G-Y) \tau_{*}\right|_{c} \equiv(G-Y) \tau_{* c d}=\left.k \frac{\delta}{d}\right|_{c}
$$

$\tau_{* c d}$ coincides with $\tau_{* c}$ in case of clear water $(\bar{c}=0)$ because the value of $G-Y$ takes unity. The following equation is obtained using Eqs. (15) and (16) assuming that the values of the right hand term, $k(\delta / d)_{c}$, of those equations are uniquely determined and take some constant value.

$\frac{\tau_{* c d}}{\tau_{* c}}=\frac{1}{G-Y}$.

Figure 6 shows relationship between depth-averaged sediment concentration, $\bar{c}$, and non-dimensional parameter, $\tau_{* c d}$. In this calculation, physical parameters are set as follows: $\sigma / \rho=2.62, \phi_{s}=34^{\circ}$ and $\tau_{* c}=0.05$. Herein, those calculated line is obtained by changing flux sediment concentration, $c_{f}$, into depth-averaged sediment concentration, $\bar{c}$ because the velocity profiles in case of $d>d_{0}$ as shown in Fig. 3 are similar to those over rigid bed. Those changes are conducted using profiles of sediment and velocity, which are solved numerically by substituting Eqs. (7) to (12) into Eqs. (3) and (4) (Egashira, 1997b).

It is quite interesting that $\tau_{* c d}$ increases with increase of depth-averaged sediment concentration, $\bar{c}$, and decrease with bed slope, $\theta$. Calculated lines tend to fit with experimental data, although the experimental data are scattered. Moreover, it is reported that Shields parameter in the flow with a steep slope increases with increase of bed slope in case of clear water flow (Graf et al., 1987; Ashida et al., 1973). In contrast to those results, the calculated results using Eq. (17) tend toward decreasing of $\tau_{* c d}$ with increase of bed slope. This is to be solved in near future.

\section{Conclusions}

Flume tests and a dimensional analysis are conducted to investigate the characteristics of bed erosion. The results are summarized as follows.

(1) If the sediment size of debris flow body is same size as bed sediment, the velocity profile is that on the erodible bed in the equilibrium flow condition. However, when the bed sediment size increases, the velocity distribution becomes similar to a velocity profile in flow over the rigid bed. Those means that shear stress due to shear rate should be non-zero in case that bed sediment is coarser than sediment of debris flow body.

(2) A new parameter, that is non-dimensional effective bed shear stress, is proposed for evaluating the critical condition of bed erosion. Effective bed shear stress is defined by the difference in a value between the total shear stress and the yield stress on the bed surface. The equation for critical bed erosion, that is Eq. (17), proposed using non-dimensional effective bed shear stress. According to Eq. (17), the critical value change monotonically with sediment concentration, especially depth-averaged sediment concentration. Predictions obtained using the equation are confirmed by flume data. It tends to shift to the critical value of sediment movement in clear water flow when sediment concentration of debris flow reaches zero.

Acknowledgements. Parts of this study are supported by by Grant-in-Aid for Scientific Research of Young Scientists (B) from the Japanese Ministry of Education, Culture, Sports, Science and Technology. Helpful discussions with K. Miyamoto, University of Tsukuba, are gratefully acknowledged. In addition, the authors should be grateful to J. C. Wells, associate professor of Ritsumeikan University, who made valuable suggestions concerning English contents of this study.

Edited by: M. Arattano

Reviewed by: L. Franzi and another referee

\section{References}

Ashida, K., Daido, A., Takahashi, T., and Mizuyama, T.: Study on the resistance law and the initiation of motion of bed particles in a steep slope channel, Annuals Disaster Prevention Research Institute, Kyoto Univ., 16B, 481-494, 1973 (in Japanese).

Egashira, S., Ashida, K., Yajima, H., and Takahama, J.: Constitutive equation of debris flow, Annuals Disaster Prevention Research Institute, Kyoto Univ., 32B-2, 487-501, 1989 (in Japanese).

Egashira, S., and Ashida, K.: Unified view of the mechanics of debris flow and bed-loads, Advances in micromechanics of granular materials, Amsterdam, Elsevier, 391-400, 1992.

Egashira, S.: Mechanism of sediment deposition from debris flow (part 1), Journal of the Japan of the Society of Erosion Control Engineering, 46, 1, 186, 45-49, 1993a (in Japanese).

Egashira, S.: Mechanism of sediment deposition from debris flow (part 2), Journal of the Japan of the Society of Erosion Control Engineering, 46, 2, 187, 51-56, 1993 b (in Japanese). 
Egashira, S., Miyamoto, K., and Itoh, T.: Bed-load rate in view of two phase flow dynamics, Ann. Jour. Hydr. Eng., JSCE, 41, 789-797, 1997 (in Japanese).

Egashira, S., Miyamoto, K., and Itoh, T.: Constitutive equations of debris flow and their applicability, Proc. 1st Int. Conf., DebrisFlow Hazards Mitigation, New York: ASCE, 340-349, 1997.

Egashira, S., Honda, N., and Itoh, T.: Experimental study on the entrainment of bed material into debris flow, Phys. Chem. Earth (C), 26, 9, 645-650, 2001.

Graf, W. H. and Suszka, L.: Sediment transport in steep channel, Jour. Hydroscience and Hydr. Eng., JHHE, 5, 1, 11-26, 1987.

Itoh, T. and Egashira, S.: Comparative study of constitutive equations for debris flows, Jour. Hydroscience and Hydr. Eng., JHHE, 17, 1, 59-71, 1999.

Miyamoto, K.: Mechanics of grain flows in Newtonian fluid, Ph.D.thesis presented to Ritsumeikan Univ., 1985 (in Japanese).
Nakagawa, H., Takahashi, T., Sawada, T., and Satofuka, Y.: Design hydrograph and evacuation planning for debris flow, Annuals Disaster Prevention Research Institute, Kyoto Univ., 39B-2, 347-371, 1996 (in Japanese).

Takahashi, T., Nakagawa, H., and Satoh, H.: Fan formulation due to the runoff of the debris and immature debris flows, Proc. 32nd Japanese Conference on Hydraulics, JSCE, 497-502, 1988 (in Japanese).

Takahashi, T. and Kuang, S. F.: Formation of debris flow on varied slope bed, Annuals Disaster Prevention Research Institute, Kyoto Univ., 29B-2, 343-359, 1986 (in Japanese).

Takahashi, T.: Debris flow, IAHR Monograph Series, Rotterdam: Balkema, 1991. 